\title{
LA IGLESIA, DON DE MISERICORDIA
}

DOI: https://doi.org/10.52039seminarios.v61i215.159

MARIO DELPINI*

PREMISAS

La impresión de un anacronismo

El tema de la misericordia parece suscitar en la sensibilidad de nuestro tiempo una especie de hastío. La misericordia, en efecto, alude a una benevolencia gratuita y dispuesta a la comprensión y al perdón. Pero parece que la gente de nuestro tiempo, al menos en una primera impresión, no está en la actitud de quien se siente en pecado, sino más bien molesta y por eso no se alegra al encontrar un abrazo misericordioso. Al contrario, su postura espontánea es la de quien siente que le deben algo y busca ser resarcido, siente que tiene el derecho y la razón y exige que se le reconozca. No es el herido que pide socorro y está agradecido por cada gesto de atención y cada cuidado, sino más bien el ofendido que quiere hacer valer su derecho a recibir excusas por el error cometido contra él.

Cuáles sean después las ofensas y los errores es difícil de concretar, pero se puede citar un poco de todo: la impresión de que la vida no mantiene sus promesas, que Dios es el responsable de ello; la memoria confusa de una historia de la Iglesia infiel a su misión, que ha perjudicado a la humanidad hasta en las cosas mínimas y en las desgracias personales y por las cuales -según la percepción del hombre de nuestro tiempo que siempre reacciona con un "seguro que no soy yo »- debe culpabilizar a alguien.

Por eso identificar la Iglesia como la casa de la misericordia, el hospital de campaña en el que se curan las heridas, y poner en la misericordia el corazón del misterio del Padre, puede sentirse como un anacronismo para la propia Iglesia y su misión, y como una hipótesis no necesaria para el misterio de Dios.

\footnotetext{
* Mario Delpini es el Obispo auxiliar de Milán.
} 


\section{El argumento para una pretensión}

La auto-presentación de la Iglesia como don de misericordia parece ser un argumento que pretende un acercamiento a la sensibilidad contemporánea. Si efectivamente se identifica la misericordia como una condescendencia incondicional, una solicitud maternal, cuyo único criterio es que el niño no llore o que el adolescente no proteste, entonces el hombre moderno (no se sabe si se trata de un niño travieso o un adolescente rebelde) solo espera de la Iglesia que apruebe todo lo que piensa y quiere, que le ayude en todo lo que necesite. Lo que pide no se presenta como una humilde súplica de alguien que sabe que no tiene derecho a nada, y por tanto espera en la bondad de Dios y de su Iglesia, sino con la pretensión de ser obligatorio, cumplido y satisfecho, bajo el supuesto de tener derecho a ello.

Las condiciones para no caer en una mala interpretación son éstas:

En lo que se refiere a las fuentes. La palabra "misericordia», como todas las palabras, corre el riesgo de ser entendida no como la revelación del Evangelio, sino según las expectativas del destinatario. El Evangelio intenta llamar a la puerta para renovar la vida del interlocutor, haciéndolo partícipe de la vida de Dios, Padre misericordioso y clemente. La expectativa del destinatario es, en cambio, estar tranquilo sin ser molestado, para sentirse confirmado en sus elecciones $y$, eventualmente liberado de los síntomas molestos y los desagradables efectos colaterales que las decisiones provocan. Para entender el significado evangélico de la piedad, más aún, para entender cómo el Evangelio tiene en su centro la misericordia, no hay otro camino que el de volver a leer el Evangelio.

G. Angelini escribe: «La verdad del Evangelio de la misericordia sólo la entienden los que tienen hambre y sed de la justicia, o, en otras palabras, sufren a causa de su pecado. El mensaje de la misericordia corre el riesgo de no ser entendido, precisamente por falta de esa clase de hambre. La misericordia esperada por la mayoría es la que remedia el sufrimiento, pero no el pecado. En este sentido, el anuncio de la misericordia tiene el efecto de tranquilizar, no de convertir» ${ }^{1}$.

\section{Realizar procesos de liberación}

La lectura del Evangelio no es la consulta de un manual, sino la escucha de la palabra de Jesús que anuncia el cumplimiento de la promesa del Reino y hace posible la decisión de entrar en el Reino a través de la 
puerta, y recorriendo el camino, que es el mismo Cristo. Esta dinámica de conversión es un ejercicio de libertad. El hombre que encuentra a Jesús y su Iglesia como la palabra del Evangelio aprende algo acerca de sí mismo: estoy llamado a elegir y mi elección decide mi identidad. A propósito de la misericordia: practicar la elección es la condición que le permite no cerrarse al aspecto emotivo e instintivo para llegar a un actuar que sea misericordioso, como es misericordioso el Padre, que está en los cielos. «Sentir compasión por quien está herido es cosa de todos, no depende de la virtud; la compasión expresa un mensaje; para comprender es necesario acercarse y aceptar la cercanía; por esta elección el mensaje de la compasión adquiere forma. Sobre todo a través del gesto el afecto dice una palabra y sella una alianza $»^{2}$. En el Evangelio de la misericordia está, por tanto, la señal, la invitación y la condición para un camino de liberación que conduce a la experiencia de la libertad que elige y eligiendo comprende y practica la misericordia.

\section{LA IGLESIA POR LA EXPERIENCIA ECLESIAL DE LA MISERICORDIA}

\section{La salvación por el individualismo}

En contra de una tendencia -se diría que difícil de erradicar-a un «consumo individual» de la misericordia, la Iglesia es un don de la misericordia, ya que proporciona el contexto comunitario sin la cual no puede lograr la reconciliación. El consumo individual se practica claramente no tanto en la forma, cuanto en la actitud con la que se vive a menudo el sacramento de la reconciliación. El penitente acceda a un servicio como una persona que quiere arreglar su conciencia, tomar el pulso a su camino, encontrar consuelo a su dolor, pide consejo para que le animen a tomar una decisión, expresar el arrepentimiento o la decepción por haber caído en «pecados habituales», poder acceder a la comunión.

El contaminante que afecta a todos estos aspectos, incluso legítimos, es el individualismo rampante. Es evidente que el sentido de Iglesia se expresa al menos por el hecho de dirigirse a un ministro de la Iglesia. Pero entre los penitentes habituales y extraordinarios la presencia del ministro de la Iglesia no es percibida como tal, es decir, como una expresión de una comunidad que acoge y que celebra la misericordia del Señor, sino como un hombre fiable, interlocutor deseable o incluso como empleado

2. C. Angelini, ibid., 680. 
habilitado para una actuación («confesarse») que por lo general se percibe como cargo y beneficio exclusivo de cada uno. Este énfasis individualista es -con toda evidencia- una mixtificación de la revelación del Evangelio de la misericordia que el Padre ejerce para el pecador arrepentido. Porque (en la parábola de Jesús) el padre para recibir al hijo que regresa organiza una fiesta para toda la casa y reintegra al pecador en el ámbito familiar: que sea verdaderamente hijo y por tanto verdadero hermano.

\section{La misericordia y la fraternidad}

El ejercicio de la misericordia no es la práctica de una limosna que el señor rico deja caer como unas monedas en las manos de los pobres. Es, más bien, la oferta de una alianza que da origen (o reconstruye) las buenas relaciones en la casa común. El paralelismo que el Evangelio realiza entre el «Padre misericordioso» y el «sed misericordiosos», entre "como yo os he amado» y "amaos los unos a otros» tiene algo de vértigo y tal vez suena poco probable en el sentir común que tiene tan poca estima de la humanidad. Su principio es el don del Espíritu Santo que nos hace partícipes de la vida de Dios, la vida eterna. Pero uno de los resultados de este paralelismo es que el amor ofrecido permite ofrecer amor. Los informes no son rígidos según un mecanismo «dar-recibir» en el cual el que da es el rico, el bueno, el santo, y el receptor sigue siendo el pobre, el cautivo, el pecador. La alianza, sin embargo, le permite participar de la vida misma, «tener todas las cosas en común».

\section{La Iglesia no es un archipiélago}

El Cuerpo Místico de Cristo, construido por el cuerpo eucarístico, es un organismo vivo, unitario, es el pueblo santo de Dios con todas las tareas juntas, todas las gracias y las heridas de su historia, toda la variedad de su geografía. El riesgo que corre la Iglesia -guiada firme e infatigablemente por el Espíritu para ser siempre un solo corazón y una sola alma- de presentarse como un archipiélago de santidad aislada y antipática y de buenas intenciones, obstinadamente determinado a ignorarse, no es extraño a la historia de nuestro tiempo. En cambio, el arte de un coro, de una coral, parece un arte olvidado. El arte de la música coral es aquel que junta la sabiduría, la paciencia, la interdependencia, la pasión por el diálogo y el encuentro, la educación de las voces de los solistas, todo aquello que da vida a un coro que canta la misma canción, el himno a la gloria de Dios que conmociona al cielo y a la tierra. 


\section{El arte de la conversación}

Un vivir «coral» es muy natural en el grupo homogéneo que comparte los mismos valores, habla el mismo idioma, da el mismo valor a los días del calendario, y comparte el mismo aprecio por las tradiciones matrimoniales, alimentarias, pedagógicas y religiosas. Pero donde se reúnen diferentes pueblos, que hablan idiomas mutuamente ininteligibles y confrontan sus propias tradiciones para demostrar quién es mejor, tejer las relaciones de la vida comunitaria, es arduo, a menudo frustrante y siempre a costa de una larga fatiga y una visión clarividente. Se requiere la práctica del arte de la conversación. La conversación es la manera de hablar que rehúye la proclamación de principios abstractos y la reivindicación de derechos de primogenitura y preferencias. La conversación rechaza incluso aquel hablar que es la cháchara, ese hablar que no dice nada, tal vez por temor a ofender las susceptibilidades de los demás o quizás, más probablemente, porque no sabe qué decir. La conversación es en cambio un «estilo medio» entre la alta retórica y la vacua banalidad. Pero el estilo no es un recurso retórico, una especie de etiqueta, sino una disposición espiritual, que se apasiona con la empresa de establecer relaciones, propiciar encuentros, de promover un diálogo en el que los interlocutores se comprometen, como fascinados por la intuición de que sea posible efectivamente preparar juntos un camino en el desierto que conduzca a la tierra prometida. La conversación presupone una estima recíproca, una especie de libertad del amor propio que hace susceptibles, temerosos del riesgo de tener que admitir que estaba equivocado, una especie de intuición de la verdad, que la sabe reconocer, incluso cuando la dicen otros. La conversación presupone la confianza en la posibilidad de que la gente tiene que hablar para entenderse en lugar de argumentar, para edificarse en lugar de exhibirse, con el fin de llegar a decisiones compartidas, en lugar de adaptarse a compromisos que desagradan a todos.

\section{Se buscan trabajadores de la misericordia}

El Jubileo extraordinario de la misericordia será una gracia que dejará semillas prometedoras y frutos duraderos si se envían los trabajadores de misericordia, dedicados al arte de la coralidad no como un hecho, episódico (que, en efecto puede armar un coro con un solo toque) sino como la vocación de toda una vida. Debiendo publicar un bando para el reclutamiento de obreros especializados en coralidad, que quizás se podría proclamar así: 
«Se buscan hombres y mujeres, pero no se excluyen ni los niños ni las niñas, ni los ancianos ni las ancianas, pero que, apenas abren los ojos al nuevo día, tienen una sola palabra que decir: ¡Gracias! En efecto, están convencidos de haber recibido la misericordia que no merecen pero que desean de todo corazón.

Se buscan hombres y mujeres que se confiesen alérgicos a lamentaciones; que encuentren insoportables los lugares comunes y los juicios sumarios y generalizados; que, frente a las personas, a las situaciones y a los acontecimientos, estén decididos a adoptar una actitud benévola, mejor que un juicio severo.

Se buscan hombres y mujeres que asuman la tarea de hacer de la palabra un regalo en lugar de un arma, una posibilidad de construir en lugar de una herramienta de demolición, el arte de tener relaciones y profundizar en ellas en lugar de la resignación a la banalidad, la inclinación a la discusión y al enfrentamiento. Con la palabra sabemos alentar en lugar de criticar, sembrar sonrisas, en lugar de malhumor, expresar estima, en lugar de insinuaciones maliciosas.

Se buscan hombres y mujeres que vivan cada momento como una oportunidad para el bien, no como una propiedad privada para ser reclamado. Por eso que tengan tiempo para escuchar, incluso a la gente aburrida, que tengan tiempo para pararse a prestar ayuda, si es necesario, incluso para los extraños, que tengan tiempo para compartir pensamientos y esperanzas para la ciudad en la que viven, aun cuando ya tengan muchos compromisos.

Se buscan hombres y mujeres que no se den demasiada importancia y por lo tanto no concedan demasiado peso incluso a cualquier palabra torpe que se les dice sin meditarla, que no sean demasiado susceptibles, incluso si reciben críticas infundadas y están siendo objeto de antipatías incomprensibles.

Se buscan personas propensas a la alegría: encontrar alegría en dar alegría a los demás y estar tan inmersos en Dios que encuentren en Él una fuente invencible e incontenible de alegría. Las personas felices por haber confiado a Dios su deseo de ser felices están más dispuestas a participar en lo que pueden ayudar a otros que en encontrar lo que buscan.

Se buscan hombres y mujeres que entiendan la misericordia como un regalo que ofrecer y no un privilegio que esperar.

Se buscan hombres y mujeres que den fe, con toda sencillez, a la verdad de la palabra que dice 'bienaventurados los misericordiosos'». 
LA IGLESIA, «MISIONERA» RESPONSABLE DE LA MISERICORDIA

Palabras sospechosas

La identificación de la Iglesia con la misión, así como el hecho de hacer consistir esa misión en la misericordia, promueven un ejercicio de responsabilidad mutua, ejercicio que parece fácil. Sin embargo, en realidad incluso las palabras irrenunciables pueden llegar a volverse sospechosas o tan vagas que resulten inofensivas, o más bien que no signifiquen absolutamente nada.

Una de estas palabras es «misión»: se convierte en sospechosa, ya que parece indicar una obligación de incordiar, una tarea que es invasora, una presunción que tiene la pretensión de imponerse como maestros de los otros. Tal vez por eso cuanto más se repite la palabra tanto menos se proponen caminos adecuados para su comprensión y para una práctica ordinaria del ser misioneros. Podemos esperar que el año de la misericordia pueda propiciar una reflexión convincente sobre qué es lo que significa ser «misioneros de la misericordia».

"ld y bautizad a todos los pueblos, enseñándoles a guardar todo lo que os he mandado» (Mt 28, 19-20).

La palabra de Jesús es perentoria, y en su formulación no parece tener en cuenta las preocupaciones de los discípulos de hoy en día, ni las objeciones previsibles de los destinatarios. Podemos imaginar que la tradición cristiana, con todas sus reflexiones y experiencias, tiene elementos para hacer frente a los problemas que surgen y para abrir un boquete en el muro tras el cual parece estar encerrada la comunidad cristiana. Para indicar al menos una pista que parece aconsejable en la ejecución de la orden de Jesús, podemos aventurar la consigna que propone el «nuevo humanismo».

Los discípulos de Jesús se convierten en testigos del nuevo humanismo, es decir, de la forma de ser hombres y mujeres que se ajusta a la humanidad de Jesús, y de este modo realiza la intención original del Creador, que quiere el hombre a su imagen y semejanza. La misión puede ser planeada y practicada como obediencia a Jesús que envía a sus discípulos a todas las naciones, a todos los pueblos, con el fin de proponer y hacer viable el ser hombres y mujeres que se conformen al hombre perfecto, que es Jesús. Precisamente esta es la obra de misericordia confiada a la Iglesia: revelar a los hijos de los hombres la altura de su vocación y demostrar su viabilidad. 
Los contenidos de este «modo de ser hombres y mujeres» deben ser detalladamente descritos, porque el humanismo cristiano no es una idea, sino una práctica. La descripción analítica, por otra parte, no es una enciclopedia, sino que es un estilo de vivir cotidiano que se desarrolla en todas las situaciones y en todos los niveles de responsabilidad, en todos los ambientes y en la tradición cultural.

Al proponer "un estilo de vida en la cotidianidad», la misericordia está presente como el alma y el principio fundamental del estilo. Los trabajadores y misioneros de la misericordia deberán evitar el riesgo de conformarse con anotar aquello que «se debe hacer», donde, en general, parece que se habla sobre todo de lo que tienen que hacer los otros. Y tendrán que estar alerta sobre el riesgo de llenar calendarios con iniciativas inéditas o repetitivas, de reuniones y celebraciones. Todas las cosas tienen alguna utilidad. Pero, en esencia, el nuevo humanismo, que se ajustan a la humanidad de Jesús, es la práctica diaria de las relaciones, compromisos, atenciones, gratuidad, celebraciones, proximidad y compartir el dolor, alegrías y esperanzas.

\section{La impermeabilidad y la sed}

Los que se dedican a la misión de anunciar el Evangelio de la misericordia a veces se desaniman por la impresión de que la gente de este tiempo es impermeable: escucha todo, pero no se deja penetrar, ve todo, pero la emoción y la participación sigue siendo una emoción pasajera, que es fácil de llevar de aquí para allá por una especie de inercia en la dinámica del grupo de pertenencia, pero sin decidirse en una dirección concreta. En esta experiencia frustrante de la inutilidad de las propuestas y programas educativos no hay soluciones fáciles.

La propuesta que insiste en «la familia como sujeto de evangelización» indica una perspectiva que merece ser profundizada, animada, acompañada. Tal vez incluso -como le gusta decir al Cardenal Angelo Scola- merezca ser tomada como un principio de «reforma» de la Iglesia. De hecho, se sugiere que el Evangelio de la misericordia se convierte en forma de la vida, si la vida ordinaria, en sus signos más habituales, revela su esplendor. El Espíritu de Dios predispone a la palabra de la misericordia, haciendo renacer la sed y alimentando el asombro por el hecho de existir para una vida recibida, de ser amados, mimados, perdonados, corregidos, alentados, y por la experiencia de ser capaces y llamados a amar, cuidar, perdonar, corregir, alentar. 


\section{Hacia el perdón}

El perdón es el acto de la misericordia cuando se vive el sufrimiento inesperado, la ofensa inmerecida, no como una agresión que justifica la reacción y la ruptura que rompe o corrompe, sino como un dolor en busca de un alivio y una herida de la que puede manar "sangre y agua». La imagen de Jesús crucificado que perdona y se convierte en fuente de vida nueva anuncia que sólo hay una posibilidad de remediar el mal: es el camino de Jesús. De la herida brota la sangre de la nueva alianza y quien se deja lavar por ella llega a ser capaz de hacer, del mal recibido y de la ofensa inmerecida, un punto de partida para una nueva forma de relación ofrecida también como alianza a aquel que ofende.

Se podría decir que el perdón es como el ápice de la misericordia, su máxima expresión: para ello se requiere un ejercicio generalizado de las obras de misericordia que se convierten en un modo de habituarse a morar en el "estilo de Jesús», para llegar a participar de sus sentimientos y capacitarse así también para el perdón.

La Iglesia que tiene la responsabilidad de anunciar la misericordia y el perdón acaso conseguirá de esa manera proponer de nuevo la práctica del sacramento de la reconciliación. La impresión -como decíamos más arriba- es que la reducción de la práctica del sacramento a una forma devocional, vivida mayoritariamente de modo individualista, buscando más la tranquilidad de conciencia que el perdón, puede haber hecho menos comprensible e incluso poco practicable el perdón mutuo. 